45 (1) | 2016

En el río del Maíz (Madre de Dios)

Homenaje a Bernard Lelong

\title{
Los asháninkas y la violencia de las correrías durante y después de la época del caucho
}

Les Ashaninka et la violence des correrías durant et après l'époque de l'extraction du caoutchouc

The Ashaninka and the violence of correrías during the rubber boom and afterwards

\section{Oscar Espinosa}

\section{(2) OpenEdition Journals}

\section{Edición electrónica}

URL: http://journals.openedition.org/bifea/7891

DOI: 10.4000/bifea.7891

ISSN: 2076-5827

Editor

Institut Français d'Études Andines

\section{Edición impresa}

Fecha de publicación: 1 abril 2016

Paginación: 137-155

ISSN: 0303-7495

Referencia electrónica

Oscar Espinosa, «Los asháninkas y la violencia de las correrías durante y después de la época del caucho », Bulletin de l'Institut français d'études andines [En línea], 45 (1) | 2016, Publicado el 08 abril 2016, consultado el 05 noviembre 2020. URL : http://journals.openedition.org/bifea/7891 ; DOI : https://doi.org/10.4000/bifea.7891

\section{(). $(\mathcal{Q} \Theta \Theta$}

Les contenus du Bulletin de l'Institut français d'études andines sont mis à disposition selon les termes de la licence Creative Commons Attribution - Pas d'Utilisation Commerciale - Pas de Modification 4.0 International. 


\title{
Los asháninkas y la violencia de las correrías durante y después de la época del caucho*
}

\author{
Oscar Espinosa*
}

\section{Resumen}

A lo largo de los siglos, el pueblo asháninka ha enfrentado diversos episodios de violencia, algunos de los cuales han afectado de manera especial la historia y la identidad de este pueblo. Uno de estos momentos fue el de la colonización de la región de la Selva Central peruana, a fines del siglo XIX, marcada por la extracción del caucho y el cultivo de café en grandes haciendas. Esta época se caracterizó, además, por ser particularmente violenta, sobre todo debido a las continuas correrías que aterrorizaban y diezmaban a las comunidades indígenas. Este episodio pone también en cuestión el rol cumplido por los propios asháninkas a los que simultáneamente viajeros e intelectuales de la época calificaban de feroces salvajes o de amables y dóciles. Finalmente, las correrías y la crueldad de esta época se siguen recordando hoy en día, relacionándose con la violencia de Sendero Luminoso y con las amenazas crueles que los asháninkas siguen enfrentando hoy.

Palabras claves: asháninka, violencia, correrías, caucho, Sendero Luminoso, misioneros franciscanos, viajeros, ethnohistoria, Amazonía, Perú

* Quiero agradecer especialmente los comentarios de Juan Pablo Sarmiento y Chris Hewlett, quienes leyeron una versión previa de este artículo y a Eduardo Fernández con quienes hemos conversado ampliamente sobre estos temas en los últimos años.

** Profesor del Departamento de Antropología de la Pontificia Universidad Católica del Perú (PUCP). E-mail: oespinosa@pucp.edu.pe 


\title{
Les Ashaninka et la violence des correrías durant et après l'époque de l'extraction du caoutchouc
}

\author{
Résumé
}

Au cours des siècles, les Ashaninka ont fait face à divers épisodes de violence. Certains d'entre eux ont eu des incidences, tout spécialement sur leur histoire et leur identité. Un de ces épisodes de violence se situe à la fin du 19 ème siècle au moment de la colonisation de la partie centrale de la forêt amazonienne au Pérou, de l'extraction du caoutchouc et des grandes haciendas de café. Au cours de ces années, les Ashaninka ont été victimes de la cruauté des raids ou correrías qui ont terrorisé et décimé leurs communautés. Cet épisode remet en question le rôle joué par les Ashaninka eux-mêmes qui étaient considérés par les voyageurs et les intellectuels de l'époque à la fois comme de féroces sauvages ou comme des personnes aimables et dociles. Finalement, les Ashaninka se souviennent encore aujourd'hui des correrías et de la cruauté de cette époque, associée à la violence du Sentier Lumineux et aux menaces auxquelles ils doivent toujours faire face.

Mots-clés : Ashaninka, violence, correrías, caoutchouc, Sentier Lumineux, missions franciscaines, voyageurs, ethnohistoire, Amazonie, Pérou

\section{The Ashaninka and the violence of correrías during the rubber boom and afterwards}

\begin{abstract}
Throughout the years, the Ashaninka people have dealt with different episodes of violence, some of which have shaped the way in which they understand their own history and identity. One of these episodes of violence took place at the end of the 19th Century, and was brought about by the process of colonization of the Peruvian Selva Central by the participants in the rubber boom and the large coffee haciendas. These years were particularly violent, and Ashaninka communities were terrorized and decimated by constant raids (correrías). This episode problematizes the role played by the Ashaninka themselves, who at the time were either seen as fierce savages or as gentle and docile by travelers and intellectuals. The heritage of these years of raids and violence are still remembered today, and they are also linked, by the Ashaninka, with the violence suffered from Shining Path and from the menaces encountered today from projects that endanger their lands and their lives.
\end{abstract}

Keywords: Ashaninka, violence, rubber boom, Shining Path, Franciscan missions, travelers, ethnohistory, Amazon region, Peru

Hoy en día los asháninkas se definen a sí mismos como un pueblo guerrero. El conflicto armado interno vivido en el Perú hace pocas décadas es uno de los diversos episodios de violencia que han tenido que enfrentar a lo largo de la historia. Según los propios asháninkas, son varios los momentos más importantes de su historia donde se constituyen como un pueblo guerrero: la rebelión de Juan Santos Atahualpa contra los españoles en el siglo XVIII, la época de las haciendas y del auge del caucho a fines del siglo XIX y principios del siglo XX, y la lucha 
contra Sendero Luminoso a fines del siglo XX1. Estos eventos se viven y expresan de diferente manera en las distintas áreas donde se encuentran las comunidades asháninkas, pero en términos de su construcción como «pueblo guerrero», constituyen hitos importantes². Pero, además, esta última experiencia de violencia política con Sendero Luminoso ha hecho que esta memoria se mantenga viva e incluso que se fortalezca, estableciéndose una continuidad con la violencia experimentada en épocas previas.

Una de las razones que explica la historia de violencia sufrida por la sociedad asháninka es su estratégica ubicación geográfica en el piedemonte amazónico en la zona central del Perú. Por ello, sus tierras han sido invadidas una y otra vez, y han tenido que luchar y defenderse en muchas ocasiones. Por ello, es un pueblo que hoy en día se enorgullece por sus buenos guerreros. Sin embargo, a pesar de considerarse como «pueblo guerrero», no es una sociedad que se define exclusivamente a partir de la experiencia de la guerra, como ocurre con otras sociedades amazónicas (como la awajún o achuar).

Las crónicas de los primeros españoles que llegan a territorio asháninka presentan, sin embargo, una imagen pacífica de este pueblo. El jesuita Font indica que son «de lindo rostro, vivo y alegre» e insiste en su gran hospitalidad:

[su jefe] nos envió dos veces refresco de comida al camino, y en su casa nos recibió con flautillas bien concertadas (Varese, 1973: 115-122).

El conquistador Fernando Contreras añade:

la gente es amable y de buenos talles y caras; son españolados y rrisueños y amorosos; muy dóciles y rreducibles [...] generosos y dadibosos; [...] no saben mentir, son muy confiados y no saben hurtar... (sic) (Varese, 1973: 131).

Finalmente, el franciscano Biedma, los describe como «graves en el aspecto, pero afables en su trato» (Biedma, 1981: 141).

La imagen del asháninka como guerrero fiero se va a ir construyendo con el tiempo. Especialmente después de la rebelión de Juan Santos Atahualpa, como sugiere Stefano Varese, va a acentuarse esta imagen de los asháninkas como «guerreros temibles que ignoran toda manifestación humanitaria, que desconocen la piedad filial» (Amich, 1988: 51). Los testimonios que brindan esta imagen de salvajismo se multiplican a lo largo de los siglos XIX y XX, tanto por los misioneros franciscanos, como por algunos viajeros (Espinosa, 1993; 2012).

Al parecer, los años de la explotación del caucho a fines del siglo XIX y comienzos del siglo XX, terminaron de fraguar esta imagen del asháninka como fiero guerrero. En esta época los asháninkas se vieron envueltos en una vorágine de violencia

1 En algunas zonas y entre algunas personas muy mayores, se incluye también el episodio de las guerrillas de 1965 como parte de este tercer evento importante, aunque en general este ha quedado opacado por la magnitud de la experiencia de la guerra contra Sendero Luminoso.

2 Esta selección de eventos históricos no se contradice necesariamente con otras formas de periodizar su propia historia como la que presenta Sarmiento (2011). 
que ha dejado huellas hasta el día de hoy, tal como podemos encontrar en los testimonios de los propios asháninkas.

\section{ENTRE EL CAUCHO Y EL CAFÉ: LOS ASHÁNINKAS Y LA COLONIZACIÓN VIOLENTA DE LA SELVA CENTRAL}

A diferencia de otras regiones, se conoce menos sobre lo que ocurrió durante la época del auge o «boom» del caucho en la Selva Central, como lo que ocurrió por ejemplo en el Putumayo o en otras regiones de la Amazonía. En realidad, el caso del Putumayo es excepcional en términos de la abundancia de materiales y testimonios que tenemos gracias al juicio entablado contra el cauchero Julio César Arana y la atención internacional que este produjo. Si se hubiera juzgado a otros caucheros localizados en la región central y sur de la Amazonía, como a Carlos Fermín Fitzcarrald, Carlos Scharff o Nicolás Suárez, se tendría más información sobre estas regiones.

Pero, además, a diferencia de Loreto, la extracción del caucho no era la principal ni la única actividad económica que se desarrolló a fines del siglo XIX en la Selva Central. Esto se debe, en parte, a que la región de selva alta que corresponde a una parte importante del territorio tradicional asháninka no es la más propicia para encontrar los árboles de siringa que producen el caucho. Es también porque en esta misma época se estaba consolidando en la región de Chanchamayo una importante hacienda productora de café que iba a transformar para siempre la vida de las comunidades asháninkas de la zona.

Desde mediados del siglo XIX, la Selva Central había comenzado a ser un espacio privilegiado por el Estado peruano para promover la colonización, especialmente por parte de migrantes extranjeros. Este proceso se hizo posible gracias a la violencia ejercida contra la población asháninka que habitaba en este territorio desde hacía siglos. En la década de 1840 se inició la colonización del valle de Chanchamayo. Primero se instaló un fuerte militar en San Ramón3, para así poder colonizar el resto de la región. Los misioneros franciscanos, por ejemplo, señalan que había dos compañías militares con cañones que «disparaban a todo indio campa que se asomaba en el paraje» (Izaguirre, 2003: 199). Esta agresión generó a su vez una reacción entre los asháninkas de esta zona. Como señala el padre Izaguirre, los militares «cometieron también el desmán de pasar el río Tulumayo con el intento de robar muchachos campas para su servicio; a cuyo intento los campas correspondieron con certeras flechas, hiriendo a algunos de ellos» (Izaguirre, 2003: 199).

En las décadas posteriores el número de colonos de origen extranjero, pero también de origen peruano, comenzó a incrementarse. Pero es sobre todo a partir de 1872

3 Diversos autores difieren en las fechas exactas de estos sucesos. Varese (1973: 228), tomando como fuente a Jorge Basadre, señala el año 1842 como el año de la creación del fuerte de San Ramón, mientras que Barclay (1989: 61-62) —tomando como fuente a Raimondi- y Fernández (1986: 22) indican que fue en 1847. 
que, con la llegada de más migrantes europeos, se empezó a dinamizar aún más el proceso de expansión de la colonización del territorio asháninka en manos de gente foránea (Fernández, 1986: 22; Barclay, 1989: 66-ss).

En estos años también se incrementa el clima de violencia en la región. El Estado, como parte del equipamiento básico que entregaba a los colonos, les remitía armas de fuego «para la defensa y seguridad de sus personas» (1892)4. El ingeniero Giordano, que acompañó a un emisario del gobierno italiano para visitar a los migrantes europeos en Chanchamayo, escribe en 1875 cómo «subsiste permanentemente una guerra a muerte entre estos chunchos i cualquiera que intente avanzar hacia el oriente» (Barclay, 1989: 72). De manera similar, el ingeniero sueco John W. Nystrom, contratado por el Estado peruano, escribe con asombro lo que ha presenciado en la selva peruana:

siempre nos hemos metido entre ellos con fuerza armada y demostrando hostilidad, robando e incendiando sus hogares.

Y concluye exclamando:

¿Qué criatura viviente, desde el animal más bajo hasta el hombre más civilizado, soportaría tropelías semejantes a las que se han cometido con los indios chunchos, sin intentar venganza y la defensa de sus hogares donde han nacido y crecido? (Nystrom, 1868: 55-56).

La colonización de la Selva Central, pues, no fue una empresa pacífica, como muchas veces se ha creído, sino más bien una conquista armada.

Sin embargo, la resistencia de los asháninkas no impide la continuación del proceso de colonización. En 1891, a partir de un convenio con el gobierno peruano, una empresa cafetalera británica llamada «la Colonia del Perené» de propiedad de la «Peruvian Corporation Ltd.» se estableció en dicho valle, Ilegando a poseer hasta unas 500000 hectáreas. El rol de esta empresa — que tuvo mucho poder en el Perú hasta el año 1972 por sus vínculos con diferentes gobiernos ligados a la oligarquía - ha sido clave en la historia del proceso de colonización de la región de la selva central: tanto en su articulación — vía la producción y comercialización agrícola- con el resto del país, como por las relaciones de abuso y dominación de la población indígena que habitaba en la zona.

La constitución de la «Colonia del Perené» junto con la fuerte inmigración llevada a cabo durante la segunda mitad del siglo XIX, transformaron radicalmente la situación de la población indígena de la región. Como señala un indígena yanesha: «desde esa época los cerros de Chanchamayo se ven tristes» (Barclay, 1989: 49). Desde fines del siglo XIX, entonces, los asháninkas comenzaron a ser utilizados como mano de obra en condiciones similares a las de la esclavitud, tanto en la producción cafetalera como en la explotación del caucho. Se calcula que en 1913 alrededor de 500 asháninkas trabajaban en las plantaciones, y en 1938 el número ya superaba los 2000 (Brown \& Fernández, 1991: 56-57).

4 Otras normas legales con el mismo carácter fueron dadas en 1874, 1888, 1896 (Ballón, 1991: 72). 
Para la explotación del caucho5, los patrones caucheros, al igual que en otras regiones amazónicas, combinaron métodos de castigo físico y psicológico de una gran crueldad. Uno de estos métodos consistía en apartar a los nativos de sus familiares y lugares de origen, de tal manera que perdían todo interés por la vida. Otra táctica importante fue la de promover la captura de otros indígenas o «correrías», como se discutirá con mayor detalle más adelante.

Muchos indígenas huyeron hacia zonas más inaccesibles (San Román, 1994: 161162; Huertas, 2002: 22-23). En la época del auge del caucho murieron decenas de miles de indígenas. Los asháninkas eran especialmente cotizados por los caucheros por sus habilidades para la recolección del caucho (Brown \& Fernández, 1991: 59, 63; San Román, 1994: 154). Pero, al igual que en los tiempos de los primeros misioneros y colonizadores españoles no se sometieron con tanta facilidad a esta explotación y exterminio. Durante estos años tuvieron que desplazarse y resistir a los caucheros y a los otros «indios civilizados» 6 que llegaban a sus tierras con la finalidad de esclavizarlos:

los campa trataban de resistir al avance de los blancos con todos los medios a su disposición: medios humanos y divinos. En 1896 antes de atacar a una colonia del Pangoa, el chamán aconsejaba a los guerreros de soplar fuerte contra las balas de los blancos para transformarlas en hojas de árboles, porque el soplo es acción divina, acto arquetípico. Pocos años antes los campa de las nacientes del río Pichis habían logrado recuperar parte de sus tierras. En los ataques habían muerto catorce colonos, los demás blancos habían huído abandonando la zona en manos de los indios sublevados (Varese, 1973: 250)

También existen testimonios de otros levantamientos por parte de los asháninkas contra los caucheros y colonizadores blancos. Entre estos, uno de los más grandes y significativos tuvo lugar en la zona del río Pichis, en 1913. En esta ocasión los asháninkas asaltaron los diversos asentamientos de colonos, cortando su comunicación con el valle del Perené y la costa. Según cronistas de la época, se calcula que entonces murieron unos 150 colonos (Brown \& Fernández, 1991: 69).

\section{LOS ASHÁNINKAS DURANTE LA ÉPOCA DEL CAUCHO: ¿PACÍFICOS O SALVAJES?}

Las principales referencias sobre la región provienen de los misioneros franciscanos y de algunos viajeros. En particular, hay dos testimonios que me parecen particularmente relevantes que presentan para cada uno de ellos una

5 En la selva peruana no se instalaron plantaciones dedicadas al cultivo de árboles para la extracción del caucho, sino que este se recogía en los bosques existentes, lo cual demandaba una mayor cantidad de mano de obra, en particular del indígena que, además, conocía bien cómo desplazarse en medio de la selva virgen (Varese, 1973: 243).

6 Los indios civilizados eran aquellos que se ponían al servicio de los caucheros para capturar nueva mano de obra indígena. 
visión diferente — casi contradictoria - sobre los asháninka en esta época. Se trata de las declaraciones de José Samanez y Ocampo que realizó una expedición por los ríos Apurímac, Ene, Tambo, Ucayali y Urubamba entre 1883 y 1884, a inicios de lo que se considera la época del auge del caucho en el Perú7. Por otra parte, tenemos las declaraciones del padre Gabriel Sala, misionero franciscano que realizó un viaje por los ríos Pichis, Pachitea, Ucayali y el Gran Pajonal durante 1896 y 1897, en pleno apogeo de la explotación de este recurso natural.

Es importante notar que no solamente la percepción de los asháninkas es diferente, sino que hay algunas pequeñas diferencias en relación a las fechas en que viajaron por territorio asháninka y en el recorrido que siguieron: Samanez y Ocampo desde el sur y el padre Sala desde el norte. Sin embargo, creo que las principales diferencias respecto a su manera de ver y comprender a este pueblo indígena no radican en las diferencias temporales o en las rutas seguidas, sino sobre todo en factores ideológicos.

\section{DE «CARÁCTER FEROZ»: LOS ASHÁNINKAS SEGÚN EL PADRE SALA Y LOS MISIONEROS FRANCISCANOS}

El misionero franciscano, fray Gabriel Sala fue uno de los más importantes misioneros del siglo XIX y principios del siglo XX en la selva peruana. El padre Sala nació en Manresa (España) en 1852 y llegó al Perú en 1868. Fue Prefecto de Misiones entre 1885 y 1891. Luego de su último viaje por el Gran Pajonal murió en 1898, teniendo 46 años de edad (Amich, 1988: 457n4). Reconocido como uno de los principales misioneros franciscanos de su generación, su aporte no se limitó al ámbito puramente religioso, sino que fue una personalidad pública. Debido a su experiencia en la región amazónica y a su conocimiento sobre geografía y sobre los pueblos indígenas de esta zona, se convirtió en un importante referente al respecto en círculos políticos y académicos (García Jordán, 1995: 97n80; 2001: 199).

Sin embargo, al igual que la mayoría de los misioneros franciscanos trabajando en la región amazónica, compartía con estos numerosos prejuicios respecto a la vida y costumbres de los indígenas. Esta visión básicamente negativa del indígena, era retroalimentada y reforzada a partir de sus propios viajes y experiencia, pero a veces también, podemos leer en sus escritos, descripciones que contradicen, eventualmente, sus propias conclusiones. Esto demuestra así el peso de su propia ideología etnocéntrica por encima de los datos positivos de la realidad. Podemos encontrar una muestra de esto en la siguiente anécdota:

En frente del referido señor Alfredo Belfort, vive un chuncho con una mujer huanuqueña, que se escapó de su marido, (Francisco Zevallos), que vive actualmente en el Pozuzo; y habiendo algunos preguntado á dicha mujer ¿cómo le iba con el chuncho campa? respondió «que muy bien». iHasta 
qué estremo (sic) puede llegar el despecho de una mujer caprichosa é inmoral! (Sala, 2003: 806)

La imagen negativa de los asháninkas que tenían los franciscanos - y que todavía hoy en día algunos de ellos tienen - se construyó fundamentalmente a partir de la rebelión de Juan Santos Atahualpa. El propio padre Sala, más de un siglo después, sigue marcado por esta experiencia8. En un momento de su viaje por el Gran Pajonal, el padre Sala llega a la casa del señor José, al que le confiere el título de «curaca» debido a que lo encuentra «más ilustrado y pícaro que los demás chunchos» que había conocido hasta entonces (Sala, 2003: 878). Y a pesar de que José acepta darles alimentos y acompañarlos como guía, el padre Sala comenta:

Si este hombre supiera leer y escribir podría ser tan fatal como Santos Atahualpa; es preciso pues mejorarlo, utilizarlo ó exterminarlo, dado el caso de que así conviniese á la civilización y bien general de la sociedad (Sala, 2003: 878).

El trato con los indígenas, según el padre Sala, es difícil y complicado, debido al carácter supuestamente hostil y criminal de los indígenas. Sin embargo se contradice con su propio relato, como cuando cuenta, por ejemplo, cómo es alojado y alimentado en numerosas ocasiones a lo largo de su viaje por muchas familias indígenas (Sala, 2003: 795, 816, 838, 839, 851, 860, 867, 869, 877, 878, $881,885)$. A pesar de ello, para el padre Sala —al igual que para otros misioneros los prejuicios y su ideología etnocéntrica son más fuertes.

El informe del viaje del padre Sala termina con tres apéndices en los que presenta sus conclusiones: el primero está dedicado a la «Conquista y colonización del Gran Pajonal»; el segundo, a la «Conquista evangélica de las varias tribus de la Montaña»; y el tercero y último es sobre «El régimen político en la Montaña».

Así, respecto a las posibilidades de la conversión religiosa de los indígenas, concluye:

Por lo que he visto durante este y otros viajes que he hecho entre los infieles de nuestras montañas, parece que todavía no ha llegado el tiempo de que entren por completo á la Iglesia de Dios. Muy grandes serán sus crímenes ó los nuestros ó muy profundos los juicios del Señor, cuando no se nota en todas estas gentes, tribus y naciones ninguna inclinación hacia el conocimiento del verdadero Dios (Sala, 2003: 898).

Y finalmente, de manera más general concluye su largo informe, en la sección dedicada al gobierno de la región, señalando que a los indígenas:

[...] los juzgo y tengo por capaces de cualquier crimen, del mismo modo que los gitanos. Ellos mienten como los cholos, sin mudarse de colores; roban y destruyen sus casas entre sí, como si fuesen unos verdaderos anarquistas; tienen relación con los diablos, peor que los luciferianos; se prostituyen y empuercan, como si fuesen animales. Sus dichos, sus gestos, sus diversiones y aun sus ritos; todo huele á un naturalismo y materialismo consumados.

8 Una de las imágenes más populares que circulan hoy en día sobre esta rebelión fue pintada por el propio padre Sala. Esta pintura se conserva en el convento de Ocopa. 
Unos hombres semejantes no es extraño que se opongan á la civilización y que aborrezcan de muerte á los blancos que no imitan sus brutales costumbres. Hay sus excepciones, es verdad, pero la generalidad, como he observado en este largo viaje, es como la acabo de retratar. Esto es, un chuncho quiere decir lo mismo que un hombre falso, traidor, ingrato, perezoso, tragador, vengativo é inconstante. ¿Y qué haremos con unos seres semejantes? Lo que se hace en todo el mundo: supuesto que no quieren vivir como hombres, sino como animales, tratarlos lo mismo que á éstos, y echarles bala cuando se oponen injustamente á la vida y al bien de los demás (Sala, 2003: 904).

\section{4. «GENTE BUENA Y DÓCIL»: LOS ASHÁNINKAS SEGÚN SAMANEZ Y OCAMPO}

El hacendado José Benigno Samanez y Ocampo, de fuerte carácter patriótico, estaba convencido que el Perú iba a salir de la crisis en que había caído luego de la guerra con Chile a partir de la explotación de los recursos de la selva amazónica, principalmente el caucho (Sala i Vila, 2001: 70). Según Palacios Rodríguez (1980: 7), el propio Samanez llamaba a esta región «el paraíso del Perú» (Palacios Rodríguez, 1980: 8). En una carta escrita a su amigo Tomás Polo en 1884 (el 28 de abril), exclamaba entusiasmado:

En este inmenso emporio de riqueza y de hermosura, puede fundarse un nuevo Perú: grande, rico y floreciente; y ahora más que nunca, cuando la desgracia ha sido tan constante en perseguirnos en la funesta guerra que la injusta y criminal Chile nos ha hecho y nos hace (citado por Palacios Rodríguez, 1980: 8).

Samanez no fue el primero en imaginar un futuro mejor en la Amazonía. Se podría recordar, al respecto, los sueños de tantos aventureros en búsqueda de El Dorado o de El Paititi desde el siglo XVI hasta la actualidad. Sin embargo, sí resulta de mayor relevancia el debate que se venía produciendo en el sur andino — de donde procedía y en donde vivía Samanez y Ocampo- durante el siglo XIX, sobre todo luego de la Independencia y de la debacle de la economía cusqueña basada en los obrajes coloniales (Sala i Vila, 1998; Walker, 1999). Como parte de este debate el franciscano italiano, Julián Bovo de Revello, publicó en 1848 un opúsculo en el que argumenta la importancia de la región amazónica para el futuro de esta región, tal como lo expresa contundentemente su título: «El brillante porvenir del Cusco».

Con esta perspectiva en mente, Samanez decide abandonar temporalmente su hacienda en Andahuaylas para dedicarse a explorar esta región promisoria, expedición que fue financiada con su propio dinero y en la que participaron también algunos amigos y parientes suyos. La ruta que siguió la expedición fue bajar desde Andahuaylas por el río Apurímac-Ene, continuar por el Tambo hasta Ucayali, y luego retornar por el río Urubamba hasta Cusco. 
Poco después de entrar a territorio asháninka, Samanez y Ocampo indica que «esta gente en general es muy buena y dócil». En todo caso, añade, «la pereza es el único vicio que la domina, sin el cual sería verdaderamente muy útil» (Samanez y Ocampo, 1980: 34), aunque en otra parte de su diario de viaje señala que también son «muy trabajadores y aficionados al comercio» (Samanez y Ocampo, 1980: 60). Esto resulta una sorpresa para el hacendado andahuaylino, que desde antes de iniciar su viaje, había expresado sus temores respecto a los selváticos:

Cierto es que la hoya del Eni, parece un territorio inexplorable, o vía tenebrosa, erizada de escollos y de las agudas flechas de los feroces campas que asesinaron al Padre Cimini y otros; pero el deseo de descubrir esta vía que favorece a varios Departamentos y el interés de lo desconocido, me han impulsado a llevar adelante mi proyecto (Samanez y Ocampo, 1980: 20).

Sin embargo, Samanez y Ocampo se topa con una realidad diferente a la relatada por los misioneros franciscanos y por otros peruanos. Lo que encuentra, al contrario, es la actitud amigable de los indígenas, y exclama sorprendido:

Vemos, pues, que esta gente (...) es muy distinta de lo que nos la pintaron, suponiéndola intratable y feroz como fieras. Es, por el contrario, no solo muy tratable, sino buena y generosa (Samanez y Ocampo, 1980: 54).

Samanez también reconoce que puede haber algunos indígenas violentos, a los que llama «malvados y traidores» (Samanez y Ocampo, 1980: 50). Sin embargo, esta característica parecería que no es inherente a su cultura, sino más bien a la personalidad de determinados individuos. Es más, según Samanez, esta fiereza indígena se debería a la desconfianza y a la influencia foránea:

Aunque el carácter en general de los campas es de una desconfianza ilimitada, que los lleva a veces hasta la traición, están lejos de ser malvados como se les ha creído. Sabiendo tratarlos con sagacidad, se les podrá civilizar pronto. La mayor parte de los crímenes que han cometido algunas veces han sido sugeridos por los llamados cristianos, o civilizados, de Ancco e Iquicha, y entristece ver que los que tienen trato con aquellos se han hecho malos, mientras que los que ni siquiera los conocen, son buenos (Samanez y Ocampo, 1980: 61).

Es más, para Samanez y Ocampo, los verdaderos «salvajes» no son los indígenas amazónicos sino los «cristianos civilizados», ya sea aquellos que se dedican a la explotación del caucho, o a los campesinos andinos de Ancco e Iquicha, en las alturas de Ayacucho cercanas del río Apurimac. Según Samanez:

los habitantes de los distritos de Chungui, Ancco e Iquicha tienen la costumbre de asaltar en masa, para asesinar y robar, a todo viajero que tiene la desgracia de cruzar por su territorio y caer en manos de estos infames, mucho peores que los salvajes (Samanez y Ocampo, 1980: 25-26).

Y ya desde el inicio de su viaje, la expedición de Samanez tuvo que desviarse para evitar a los peligrosos habitantes de estas regiones ayacuchanas:

Tan penosa y cruel marcha nos vemos obligados a hacer por entre bosques impenetrables y precipicios, cuya sola vista horripila, sin embargo de haber 
camino de herradura por la banda opuesta en el territorio de Ancco y Chungui, por la razón ya indicada de que sus habitantes, más feroces y malvados que los salvajes cashivos o siriniris, se oponen a todo tránsito por sus tierras (Samanez y Ocampo, 1980: 28).

Cualquiera puede ser víctima de los ayacuchanos, incluso los mismos asháninkas. Al respecto, cuenta Samanez cómo estos se tienen que alejar de las riberas de los ríos para evitar ser atacados:

En la pampa de Sinquibeni y en las faldas del cerro, que la domina, habitan varias familias de salvajes campas, los cuales hacen un pequeño comercio con los indios de Ancco; trocando cera negra, copaiba, loros y monos por herramientas y sal. Los Anccos explotan como quieren, en estos negocios, a los infieles; y lo que es peor, les roban y asaltan con el mayor descaro, sus chacras y casas, hallándose tan exasperados éstos, que se van alejando de la llanura a los cerros inmediatos, a donde no alcanza la rapacidad de aquellos bandidos (Samanez y Ocampo, 1980: 32).

Un ahijado del propio Samanez, un migrante chino de apellido Valle, que se dedicaba a la explotación del caucho en la región, también fue atacado por los campesinos andinos; este se salvó gracias a la ayuda de los asháninkas (o campa):

Desgraciadamente, apenas llegó a Sinquibeni [mi ahijado Valle], fue atacado por los indios de Ancco que, en número de seis u ocho, habían ido a ese punto con el criminal propósito de matarle y robarle.

No le hallaron felizmente en la casa de Inocencio Muláito en que se había alojado. Encontrábase a la sazón en el bosque buscando caucho. Los salvajes que estaban en la casa, se dieron prisa a esconder todo el equipaje y herramientas de Valle; pero no pudieron hacer lo mismo con un rifle Winchester, de mi propiedad, que se llevaron los asaltantes.

Como los siguiesen buscando, tuvo que permanecer oculto en los bosques por seis días, al cabo de los cuales logró escaparse guiado por los salvajes, sin cuyo auxilio habría sido victimado. He allí los civilizados! He aquí los salvajes! (Samanez y Ocampo, 1980: 106-107).

La pregunta crítica aquí es, pues, a qué se debe el clima de «desconfianza ilimitada» que menciona Samanez y cómo esta influencia foránea se traduce en respuestas violentas de los indígenas. Al parecer, habría dos razones para esta desconfianza. La primera, y posiblemente la más antigua, se refiere a las enfermedades y a la posibilidad de epidemias y de muertes masivas que se dan desde el primer contacto entre los indígenas y los europeos, sobre todo los misioneros. A fines del siglo XIX, el temor a las epidemias seguía fuertemente enraizado entre los asháninkas. Así, por ejemplo, cuenta el padre Sala cómo, al recibirlo una familia indígena en el Gran Pajonal, lo primero que preguntó el jefe de la familia fue:

¿Quiénes sois vosotros? ¿de dónde venís?; ¿por qué habéis venido á esta tierra?; ¿traéis alguna enfermedad? (...) Sin duda vosotros traéis catarro ó sarampión (Sala, 2003: 869). 
Pero posiblemente la principal razón de la desconfianza y de la violencia se encuentra en las llamadas «Correrías» promovidas por los patrones caucheros, como veremos a continuación.

\section{LAS «CORRERÍAS»: LA VIOLENCIA INTRA E INTERÉTNICA}

En un momento de su viaje, la expedición de Samanez se encuentra con la dificultad de no conseguir guías para proseguir su viaje. Cuenta el propio Samanez:

Cuando les propuse que me llevasen hasta el Chanchamayo, que aseguran veremos mañana, se negaron obstinadamente a servirnos de guías, alegando dos motivos: primero, que no podrían dejar sola su familia, por el riesgo de los tigres que dicen abunda mucho aquí. En efecto, sus casas están rodeadas de una reja de palos, mui entretejida y fuerte y tienen además hermosos perros mui bravos. Decían, en segundo lugar, que más abajo venían con frecuencia hombres vestidos con pantalones y armados de escopetas, a los que temen mucho; porque, después de encarnizados combates, les quitan sus mujeres e hijos y se los llevan (Samanez y Ocampo, 1980: 54).

A pesar de la evidencia del testimonio, Samanez se resiste a pensar que pudieran ser los propios caucheros los que se dedican a atacar los poblados indígenas:

No podemos calcular qué gente sea ésta. Ignoramos que los piros o simirinches usen pantalón y manejen armas de fuego. Más tarde lo sabremos (Samanez y Ocampo, 1980: 54).

Una resistencia similar parece tener el padre Sala, que incluso Ilega a reconocer cómo sus propias percepciones y creencias pueden modificarse al vivir en la selva:

Todos claman en contra del negocio de venta de carne humana que se hace por esas tierras; pero, desde la primera autoridad, hasta el último chacarero ó comerciante, desean tener un chunchito ó una chunchita para su servicio; y si no lo tienen, no dejan de pedirlo á cualquiera que se mete á la chunchada ó que va á las correrías; y una vez que lo consiguen, se lo agradecen muy bien y le pagan. Esto, por más que se diga, es «borrar con el codo lo que se escribe con la mano» y dar aliento á los cazadores y vendedores de chunchos á que prosigan en sus correrías. Desde Lima, y aun desde la sierra, somos unos misioneros acabados; pero puestos en la montaña, nos vamos amoldando con mucha facilidad y suavidad al sistema antiguo y costumbres de aquellas tierras... (Sala, 2003: 831).

En este sentido, la selva sería una región de «frontera», entendida no como límite entre países, sino como aquella zona en que entran en contacto el mundo «Civilizado» y el mundo «salvaje». Según Ana María Alonso (1995), la frontera se ubica en los márgenes del Estado, en un espacio abierto a la violencia. Es más, como señalan Brown \& Fernández (1992), desde la época colonial el pueblo asháninka se ha relacionado con un Estado que dista mucho de ser homogéneo en sus prácticas de dominación, y que incluso puede ser contradictorio. Así, a lo largo de la historia, los propios Estados generan, en algunas zonas más que 
en otras, como en la selva peruana, espacios donde el control de la violencia se flexibiliza. En este sentido, en el proceso de colonización y control territorial en las «fronteras», se imagina al Estado como un espacio gobernado por leyes humanas, el espacio donde puede desarrollarse la vida social y, por lo tanto, un territorio donde los límites no están claros, donde predomina la ley del más fuerte y donde se justifica el uso de la violencia con una finalidad «civilizadora». Por ello, al final, como se pregunta también Samanez y Ocampo, no se sabe muchas veces quiénes son los verdaderos «salvajes» o los verdaderos «civilizados».

Las «Correrías» fueron una táctica frecuentemente utilizada y difundida por Carlos Fermín Fitzcarrald. Consistía en enfrentar a los diversos grupos nativos aprovechándose de las rivalidades tradicionales que estos grupos mantenían entre sí. Fitzcarrald y otros caucheros premiaban a aquellos indígenas que «cazaban», literalmente, a otros indígenas - o incluso a sus propios paisanos- a cambio de bienes o favores. Al respecto, cuenta Varese que:

se entregan Winchester a los cunibo que tienen que pagar con esclavos campa, después se entregan Winchester a los campa y éstos tienen que pagar con esclavos cunibo o amuesha, y así sucesivamente en una cadena de correrías trágicas que tiñen de tristeza y horror casi cuarenta años de historia de la selva peruana y cuyas consecuencias se sienten hasta ahora (Varese, 1973: 246).

Las «Correrías» consistían en asaltos armados a lo largo de los ríos con la finalidad de capturar a indígenas, sean adultos, jóvenes o niños, muchos de los cuales morían o caían heridos, quedando a salvo solo aquellos que lograban fugar. Los que dirigían las «Correrías» eran en unos casos los mismos patrones y en otros casos contrataban a mestizos o a otros indígenas. «Luego los prisioneros eran vendidos en las llamadas «camperías» de caucheros a cambio de armas de fuego, cartuchos, tocuyo, espejos, machetes, etc.

Sin embargo, parece que la organización de correrías por parte de los asháninkas no era una práctica ancestral, sino que fue producto de la presión de los propios caucheros. Brian Ferguson (1990) ha demostrado cómo los indígenas amazónicos introdujeron prácticas guerreras por influencia de los europeos. Esto no quiere decir que previamente a la llegada de los europeos no se hubieran producido enfrentamientos armados entre indígenas, como el mismo Ferguson (1990: 238) reconoce, pero sí que en muchas sociedades indígenas se han implementado estas prácticas debido a la influencia directa o indirecta de la presencia europea. En la misma línea, Jeffrey Blick (1988) añade que, incluso en los casos en que existían prácticas violentas en sociedades indígenas, estas se acentuaron o incrementaron a partir de la presencia colonial europea. Fernando Santos-Granero (2009: 25, 29) lo confirma para el caso de las sociedades amazónicas, tanto durante la época colonial como durante la época del caucho.

Parece ser, además, que una de las características propias de los pueblos arawak sería la ausencia o evasión de conflictos o guerras al interior de la propia sociedad indígena (Hill \& Santos Granero, 2002: 17-18). Para algunos estudiosos, esto también sería cierto para el caso asháninka (Renard-Casevitz, 1993: 31; 2002: 
130; Santos-Granero 2002: 29-30). Es decir, sería perfectamente normal que los asháninkas se enfrenten a otra sociedad, pero sería casi impensable que un grupo asháninka ataque a otro grupo de paisanos asháninkas. Sin embargo, los datos históricos nos muestran que, por lo menos desde la época del caucho, esto ya no es así.

Según Gerald Weiss (1975: 239), entre los asháninkas no habría existido un sentido de solidaridad, y por el contrario, la regla habría sido la guerra intraétnica y las correrías. Weiss, sin embargo, no desarrolla un análisis histórico más fino que quizás le hubiera permitido ubicar la adopción de estas prácticas a partir de la época del caucho. Las correrías y las guerras internas se deberían, entonces, a la presión ejercida por los caucheros en su afán de obtener mano de obra, y al acceso a bienes o dinero a cambio de la captura de otros indígenas ${ }^{9}$. La incorporación de estas prácticas por los asháninkas correspondería, según Fernando Santos Granero, a un proceso de «panoización», es decir, de adopción de estas prácticas tradicionalmente empleadas por pueblos pano como los konibos, sus vecinos próximos (Hill \& Santos-Granero, 2002: 17; Santos-Granero, 2002: 32). Estas prácticas violentas han dejado, además, huellas imborrables en la memoria asháninka y en su propia autopercepción, como se verá a continuación.

\section{6. «CONTINUAS GUERRAS»: LA HISTORIA VIOLENTA DEL CAUCHO VISTA POR LOS ASHÁNINKAS HOY}

El clima de violencia instaurado por las correrías se mantuvo durante muchos años más después de haberse terminado con la época de explotación del caucho ${ }^{10}$. Así, por ejemplo, en 1924, el geógrafo sueco Otto Nordenskjöld relata la existencia de puestos de observación en lugares altos y estratégicos que sirven a los asháninkas para vigilar los ríos Ene y Tambo, por donde aparecían antiguamente los caucheros (Varese, 1973: 261-62). En 1929, el Vicario Apostólico de Ucayali, Monseñor Irazola, denunciaba las continuas «correrías» que los colonos seguían haciendo en territorio indígena (San Román, 1994: 156)11.

Hoy en día, la memoria de las correrías y de la violencia de la época del caucho sigue presente en muchas comunidades asháninkas, sobre todo en la zona comprendida entre el río Tambo, el Ucayali y el Gran Pajonal. Incluso cuando los más viejitos no hayan vivido estos episodios directamente, las historias que se han transmitido de generación en generación han mantenido vivo su recuerdo. Pero, además, la

9 Resulta interesante que la cita antes mencionada de Weiss concluye afirmando que, para los asháninkas, los «blancos» o wirakocha son odiados y temidos, constituyendo prácticamente una subcategoría de demonios, mientras que su mercancía es muy deseada (Weiss, 1975: 239).

10 La época del auge de la explotación del caucho duró en el Perú de 1880 a 1915; en Brasil comenzó unos veinte años antes. La fecha de fin es muy clara, ya que, a partir de 1915, el imperio británico empezó a producir caucho en plantaciones ubicadas en sus colonias en el sudeste asiático.

11 Todavía se han presentado casos de hacendados que esclavizaban a los asháninkas hasta fines del siglo XX (Aidesep, 1991; García Hierro et al., 1998; Sarmiento, 2011). 
experiencia de la violencia durante el conflicto armado interno ha hecho que esta memoria se mantenga viva e incluso que se fortalezca, estableciéndose incluso una continuidad entre la violencia experimentada durante la época del caucho y la violencia más reciente.

Beatriz Fabián ha recogido varios de estos testimonios en comunidades del río Tambo. Así, por ejemplo, Ángel Novoa, importante líder de la zona, le contó cómo los ovayeri12 capturaban a la gente para llevarla a trabajar a las haciendas:

a sangre y fuego, a niños, hombres y mujeres asháninkas, por patrones y hacendados y con el apoyo de algunos indígenas los sometían a esclavitud en las haciendas, ejemplo: Ratteri, Paine o Pent, Souza, Ripamonti, Núñez, Valderrama, Vargas y los paisanos vivían en la esclavitud (Testimonio de Ángel Novoa Mori, recogido por Beatriz Fabián, Satipo, 2002).

Otros culpan más bien a los ovayeri ashéninka que venían de más lejos, del Gran Pajonal:

Las correrías las hacían los pajonalinos, ellos iban hasta el río Ene, Tambo, Bajo Perené. A los asháninkas los vendían o canjeaban por escopetas y herramientas, los llevaban al río Urubamba, incluso hasta la frontera Perú con Brasil y eran entregados a patrones caucheros, madereros, ganaderos (Fabián, 2006: 77).

Un asháninka de la comunidad kakinte de Tsoroja, recordaba cómo sus antepasados tuvieron que huir hacia las cabeceras del río Poyeni:

nuestros abuelos vivían en la Boca del río Mayapo, afluente del río Tambo, después aparecieron en Alto Poyeni, porque hacían correrías los de Poyeni la familia Kamayteri, Tyonkitsiki, quienes eran jefes malos y hacían guerra a los paisanos, agarraban a las gentes y los canjeaban con los patrones por cartuchos, escopetas, machetes, ellos iban hasta río Ene, Perené, Pajonal, Tambo y a otras comunidades nativas. Por eso los kakinte vivían ocultos en las peñas (cuevas), pacavales del monte real, sin hacer camino... Fabián, 1994).

Efectivamente, la mayoría de los asháninkas que viven en el río Tambo recuerdan el tiempo previo a la existencia de las actuales comunidades como un tiempo de violencia permanente. En un folleto publicado en la comunidad de Poyeni con motivo del aniversario número 45 de su creación, se indicaba que hasta el año 1959, los asháninkas que hoy viven en esta comunidad:

12 La palabra ovayeri significa literalmente «el que dispara» (Eduardo Fernández, comunicación personal). Este término se utilizaba antiguamente para referirse a asháninkas guerreros, pero con un sentido negativo; es decir, se asociaba con aquellos que lideraban las correrías. Esto llevó a que el Instituto Lingüístico de Verano tradujera este término como «asesino»(Kindberg, 2008: 215). Durante el conflicto armado interno, los asháninkas le dieron un significado más positivo a esta palabra, al asociarlo con los ronderos. Este uso es el que predomina hoy en día, aunque también puede aparecer asociado a las correrías de antaño, tal como se puede apreciar en los testimonios aquí presentados. 
Vivían de manera dispersa, trasladándose constantemente de un lugar a otro para evitar enfermedades..., y además tenían temor por las continuas guerras entre asháninkas bajo el comando del guerrero Tyonkitsiki.

Este texto es leído hoy por los jóvenes escolares, que repiten esta historia nuevamente. Al preguntárseles a un grupo de jóvenes escolares de la comunidad de Poyeni en el año 2011, a quiénes ellos consideraban héroes, varios muchachos respondieron a la pregunta, contando la historia de su comunidad y de la lucha contra la violencia. En esta historia de violencia, la mayoría de escolares vincula explícitamente el heroísmo de los asháninkas que, por un lado, ponen fin a las «Continuas guerras Tyonkitsiki» (Tyonkitsiki, como se ha visto, era un jefe asháninka que organizaba correrías por el río Tambo), con la lucha contra los rojos o kityonkari. Varios de los jóvenes repiten casi textualmente la información impresa en este folleto elaborado con motivo del aniversario de Poyeni. Sin embargo, otros, como Boris Ríos Campos, expresa esta conexión de manera más explícita:

En el año 1964 es la primera guerra que hubo en esta comunidad y ganaron los asháninka la primera guerra y los comuneros hicieron reunión y cambiaron el nombre de la comunidad y le pusieron Poyeni, y en el año 1970 fue la segunda guerra, y por eso los asháninkas de río Tambo, de Puerto Ocopa, vinieron de Junín, se vinieron a la comunidad de Poyeni para luchar contra los Sendero Luminoso. Los asháninkas en trinchera se escondieron y ganaron la segunda guerra asháninka (Sagástegui et al., 2013: 33)13.

Otra forma en que se expresa esta memoria es a través de referencias geográficas. Todavía se recuerdan los lugares donde se encontraban las trincheras o puestos defensivos en el río Tambo, por ejemplo, aquellas ubicadas en Sotlitlajapla (en el Bajo Tambo, cerca de la actual comunidad de Impaniquiari) o en Ongoneni (en el Alto Tambo, entre las comunidades de Otika y Kamajeni). Estos lugares, que también fueron utilizados durante la época de la violencia contra Sendero Luminoso, coinciden con los lugares para divisar a los caucheros y sus correrías (Zarzar \& Román, 1983: 99, 116). Las trincheras constituyen, pues, un referente físico y material importante como testimonio de estas luchas, tal como se puede apreciar también en el relato de Boris Ríos.

Finalmente, la semejanza más trágica entre ambos episodios violentos, el de las correrías durante la época del caucho y durante los años de la violencia política, se encuentra en la posibilidad real de que un asháninka mate a otro asháninka. En el año 2010, Pedro, un joven de 18 años, indicaba:

Mis padres me contaron que en ese tiempo nadie era hermano, llegó la desconfianza. Un asháninka mata a otro. Mi tío mató a mi primo. Pero no porque él quería, sino que era obligado por los mandos [senderistas]... Por eso ya no se confía en asháninka... (Silva Huerta, 2010: 5).

13 He corregido la ortografía y gramática para hacer el texto de Boris Ríos más legible. En el libro (Sagástegui et al., 2013: 33) aparece tal como fue escrito originalmente. 
Y añade más adelante: "nadie es familia de nadie, tu hermano es el que sabe matar, tú debes matar" (Silva Huerta, 2010: 5).

La idea de que esto es posible supone, para la sociedad asháninka, un grave atentado, no solamente a sus valores morales, sino a su propia identidad. Ya que el mismo término «asháninka», que literalmente significa, «nosotros, la gente», incluye y hace referencia explícitamente a aquellos que son «hermanos» o «compañeros», a los nosháninka. La violencia destruye la hermandad, el compañerismo y la convivencia. Desgraciadamente, para los asháninkas, el tiempo de la violencia no ha terminado, en la medida en que siguen habiendo proyectos foráneos que amenazan sus territorios, sus costumbres y su vida misma.

\section{Referencias citadas}

AIDESEP, 1991 - Esclavitud Indígena en la Región Atalaya. Amazonía Indígena, 11 (17-18): 1-13.

ALONSO, A. M., 1995 - Thread of Blood: Colonialism, Revolution and Gender on Mexico's Northern Frontier, 309 pp.; Tucson: University of Arizona Press.

AMICH, J., 1988 - Historia de las Misiones del Convento de Santa Rosa de Ocopa, 590 pp.; Iquitos: Centro de Estudios Teológicos de la Amazonía (CETA), Instituto de Investigaciones de la Amazonía Peruana (IIAP). Colección Monumenta Amazónica. (Edición de Julián Heras).

BALLÓN, F., 1991 - La Amazonía en la Norma Oficial Peruana, 1821-1990, 4 vols.; Lima: Centro de Investigación y Promoción Amazónica (CIPA).

BARCLAY, F., 1989 - La Colonia del Perené. Capital inglés y economía cafetalera en la configuración de la región de Chanchamayo, 258 pp.; Iquitos: Centro de Estudios Teológicos de la Amazonía (CETA).

BIEDMA, M., 1981 - La conquista franciscana del alto Ucayali, 187 pp.; Lima: Milla Batres. Introducción y notas de Antoine Tibesar OFM.

BLICK, J., 1988 - Genocidal Warfare in Tribal Societies as a Result of European-Induced Culture Conflict. Man - New Series, 23 (4): 654-670.

BOVO DE REVELLO, J., 1848 - Brillante porvenir del Cuzco o Exposición de las esperanzas de engrandecimiento de este departamento, 81 pp.; Cusco: Imprenta Libre.

BROWN, M. F. \& FERNÁNDEZ, E., 1991 - War of Shadows. The Struggle for Utopia in the Peruvian Amazon, 280 pp.; Berkeley: University of California Press.

BROWN, M. F. \& FERNÁNDEZ, E., 1992 - Tribe and State in a Frontier Mosaic: The Asháninka of Eastern Peru. In: War in the Tribal Zone. Expanding States and Indigenous Warfare (B. Ferguson \& N. Whitehead, eds.): 175-197; Santa Fe, New Mexico: School of American Research Press.

ESPINOSA, O., 1993 - Los Asháninka: Guerreros en una Historia de Violencia. América Indígena, 53 (4): 45-60.

ESPINOSA, O., 2012 - La violencia y la historia asháninka: De Juan Santos Atahualpa a Sendero Luminoso. In: El aliento de la memoria: Antropología e Historia en la Amazonía Andina (F. Correa Rubio, J.-P. Chaumeil \& R. Pineda Camacho, eds.): 284301; Bogotá: Instituto Francés de Estudios Andinos (IFEA), Universidad Nacional de Colombia, CNRS. 
FABIÁN, B., 1994 - La autodefensa asháninka y los desplazados asháninka por la violencia política. Documento inédito.

FABIÁN, B., 2006 - La participación pública de la mujer asháninka en la cuenca del río Tambo entre 1990-2002, 208 pp.; Lima: Universidad Nacional Mayor de San Marcos-Facultad de Ciencias Sociales.

FERGUSON, B., 1990 - Blood of the Leviathan: Western Contact and Warfare in Amazonia. American Ethnologist, 17 (2): 237-257.

FERNÁNDEZ, E., 1986 - Para que nuestra historia no se pierda. Testimonios de los Asháninca y Nomatsiguenga sobre la colonización de la región Satipo-Pangoa, 213 pp.; Lima: Centro de Investigación y Promoción Amazónica (CIPA).

GARCíA HIERRO, P., HVALKOF, S., GRAY, A. \& PARADELLA, A., 1998 - Liberación y derechos territoriales en Ucayali - Perú, 224 pp.; Copenhague: International Work Group for Indigenous Affairs (IWGIA).

GARCÍA JORDÁN, P., 1995 - Las misiones católicas en la Amazonía peruana: ocupación del territorio y control indígena (1821-1930). In: La construcción de la Amazonía andina, Siglos XIX-XX (P. García Jordán, ed.); 7-106; Quito: Abya Yala.

GARCÍA JORDÁN, P., 2001 - Cruz y arado, fusiles y discursos. La construcción de los Orientes en el Perú y Bolivia, 1820-1940, 476 pp.; Lima: Instituto Francés de Estudios Andinos (IFEA), Instituto de Estudios Peruanos (IEP).

HILL, J. \& SANTOS-GRANERO, F. (eds.), 2002 - Comparative Arawakan Histories. Rethinking Language Family and Culture Area in Amazonia, 349 pp.; Urbana: University of Illinois Press.

HUERTAS, B., 2002 - Los pueblos indígenas en aislamiento. Su lucha por la supervivencia y la libertad, 256 pp.; Lima: International Work Group for Indigenous Affairs (IWGIA).

IZAGUIRRE, B., 2003 - Historia de las Misiones Franciscanas en el Oriente del Perú. Vol. IV (Tomos IX y X).; Lima: Provincia Misionera de San Francisco Solano del Perú. Edición y notas de P. Félix Sáiz, OFM.

KINDBERG, L., 2008 - Diccionario asháninca, 466 pp.; Lima: Instituto Lingüístico de Verano.

NYSTROM, J.G., 1868 - Informe al supremo gobierno del Perú, 79 pp.; Lima: Imprenta y Litografia de E. Prugue.

PALACIOS RODRÍGUEZ, R., 1980 - Prólogo. In: Exploración de los ríos peruanos: Apurímac, Ene, Tambo, Ucayali y Urubamba hecha por José B. Samanez y Ocampo en 1883 y 1884 (J. B. Samanez y Ocampo, ed.): 7-15; Lima: Tip. Sesator.

RENARD-CASEVITZ, F.-M., 1993 - Guerriers du sel, sauniers de la paix. L'Homme, 33 (126128): 25-43.

RENARD-CASEVITZ, F.-M., 2002 - Social Forms and Regressive History: From the Campa Cluster to the Mojos and from the Mojos to the Landscaping Terrace-Builders of the Bolivian Savanna. In: Comparative Arawakan Histories: Rethinking Language Family and Culture Area in Amazonia (J. Hill \& F. Santos-Granero, eds.): 123-146; Urbana: University of Illinois.

SAGÁSTEGUI, C. et al., 2013 - Cómo imagino: Manual para profesores. Comunidad Asháninka Poyeni, 86 pp.; Lima: Pontificia Universidad Católica del Perú (PUCP).

SALA, G., 2003 - Apuntes del Viaje del P. Fr. Gabriel Sala. Exploración de los ríos Pichis, Pachitea y Alto Ucayali y de la Región del Gran Pajonal (1897). In: Historia de las Misiones Franciscanas en el Oriente del Perú. Vol. IV (Tomos IX y X) (B.Izaguirre, ed.): 779-933; Lima: Provincia Misionera de San Francisco Solano del Perú. 
Los asháninkas y la violencia de las correrías durante y después de la época del caucho

SALA I VILA, N., 1998 - Cusco y su proyección en el Oriente amazónico, 1800-1929. In: Fronteras, colonización y mano de obra indígena en la Amazonía Andina (Siglos XIX-XX). La construcción del espacio socio-económico amazónico en Ecuador, Perú y Bolivia, 1792-1948 (P. García Jordán, ed.): 401-535; Lima Barcelona: Pontificia Universidad Católica del Perú (PUCP), Universitat de Barcelona.

SALA I VILA, N., 2001 - Selva y Andes: Ayacucho, 1780-1929, historia de una región en la encrucijada, 260 pp.; Madrid: Consejo Superior de Investigaciones Científicas (CSIC).

SAMANEZ Y OCAMPO, J. B., 1980 - Exploración de los ríos peruanos: Apurímac, Ene, Tambo, Ucayali y Urubamba hecha por José B. Samanez y Ocampo en 1883 y 1884, 174 pp; Lima: Tip. Sesator.

SAN ROMÁN, J., 1994 - Perfiles históricos de la Amazonía Peruana, 274 pp.; Lima: Centro de Estudios Teológicos de la Amazonía (CETA), Centro Amazónico de Antropología y Aplicación Práctica (CAAAP), Instituto de Investigaciones de la Amazonía Peruana (IIAP). 2 ${ }^{\mathrm{a}}$ ed.

SANTOS-GRANERO, F., 2002 - The Arawakan Matrix: Ethos, Language, and History in Native South America. In: Comparative Arawakan Histories. Rethinking Language Family and Culture Area in Amazonia (J. Hill \& F. Santos-Granero, eds.): 25-50; Urbana: University of Illinois Press.

SANTOS-GRANERO, F., 2009 - Vital Enemies. Slavery, Predation, and the Amerindian Political Economy of Life, 280 pp.; Austin: University of Texas Press.

SARMIENTO, J. P., 2011 - Kametsa Asaiki. The pursuit of the "good life" in an Ashaninka village (Peruvian Amazonia); St. Andrews: University of St. Andrews. Tesis de Doctorado.

SILVA HUERTA, S. 2010 - Memoria de los jóvenes Asháninka sobre el conflicto armado interno. Documento inédito.

VARESE, S., 1973 - La Sal de los Cerros. Notas Etno-gráficas e históricas sobre los Campa de la Selva del Perú, 402 pp.; Lima: Retablo de Papel. 2a ed.

WALKER, C., 1999 - Smoldering Ashes: Cuzco and the Creation of Republican Peru, 17801840, 330 pp.; Chapel Hill: Duke University Press.

WEISS, G., 1975 - Campa Cosmology. The world of a forest tribe in South America, 588 pp.; New York: The American Museum of Natural History.

ZARZAR, A. \& ROMÁN, L., 1983 - Relaciones intertribales en el Bajo Urubamba y Alto Ucayali, 121 pp.; Lima: Centro de Investigación y Promoción Amazónica (CIPA). 